\title{
PAIN AND QUALITY OF LIFE OF ADOLESCENTS WITH PRIMARY DYSMENORRHEA IN TBILISI, GEORGIA, 2008. CROSS SECTIONAL STUDY
}

\section{Dolor y calidad de vida en adolescentes con dismenorrea primaria en Tbillisi, Georgia, 2008. Estudio de Corte transversal}

Tinatin Gagua, $\mathrm{MD}^{1}$; Tkeshelashvili Besarion, $\mathrm{MD}, \mathrm{PhD}^{2}$; David Gagua, $\mathrm{MD}, \mathrm{PhD}^{3}$

Received: November $27^{\text {th }}, 2012$ - Accepted: May 24 $4^{\text {th }}, 2013$

\section{ABSTRACT}

Objective: The study aimed to measure the effect of primary dysmenorrhea on the quality of life of female adolescents living in Tbilisi, Georgia, and to compare Quality of Life (QoL) with healthy controls.

Materials and methods: Cross-sectional study of 424 women aged 14-20, living in Tbilisi, Georgia, coming from academic and research institutions. The women were divided into those suffering dysmenorrhea (exposure group) and those without pain (control group). Reproductive history, demographic features, menstrual pattern, severity of dysmenorrhea and quality of life using the generic instrument EQ-5D, were measured. The Independent $\mathrm{T}$ student test was used for group comparison.

Results: The group with dysmenorrhea (276) showed a lower Quality of Life score of $0.69 \pm$ 0.20 vs. $0.94 \pm 0.10$ in the control group ( $p=$ 0.000); the Quality of Life VAS was also lower at

1 Assistant professor Obstetrics/Gynecology Department. MedicalUniversity “Aieti”. Tbilisi, Georgia. Tinatingagua@gmail.com

2 Associate professor Obstetrics/Gynecology Department Medical University “Aieti”. Tbilisi, Georgia. btkeshelashvili@yahoo.com

3 Professor Obstetrics/Gynecology Department. Tbilisi, Georgia. Gagua80@mail.ru
$74.38 \pm 17.83$ vs. $87.02 \pm 12.03(\mathrm{p}=0.000)$. Of the subjetcs with primary dismenorrhea, $56.6 \%$ reported school absenteeism due to pain.

Conclusion: Primary dysmenorrhea is a common problem in the adolescent population of Tbilisi, Georgia. The results of this study demonstrate that adolescents with primary dysmenorrhea in Georgia experience significantly lower physical and psychosocial health-related QoL than their healthy peers.

Key words: Primary dysmenorrhea, adolescent, quality of life, EQ-5D quality-of-life test.

\section{RESUMEN}

Objetivo: el objetivo del estudio fue determinar el efecto de la dismenorrea primaria sobre la calidad de vida de las mujeres adolescentes de Tbilisi, Georgia y comparar su calidad de vida con la de quienes no presentan dismenorrea.

Materiales y métodos: estudio de corte transversal llevado a cabo en 424 mujeres entre 14-20 años residentes en Tbilisi, Georgia, y pertenecientes a una institución académica y de investigación. Las adolescentes se dividieron entre quienes sufrían de dismenorrea (grupo expuesto) y quienes no tenían dolor (grupo control). Se midieron las características demográficas, la historia reproductiva, el patrón 
menstrual y la gravedad de la dismenorrea. La calidad de vida se midió con el instrumento EQ-5D; se utilizó la prueba t de Student para las variables independientes.

Resultados: el grupo de mujeres con dismenorrea (276) mostró una menor calidad de vida de 0,69 \pm 0,20 frente a $0,94 \pm 0,10$ para el grupo de control ( $\mathrm{p}=0,000)$, y también una menor calidad de vida con la Escala Visual Análoga del instrumento de Calidad de Vida (Quality of Life VAS) con valores de $74,38 \pm 17,83$ frente a 87,02 $\pm 12,03(\mathrm{p}=0,000)$. El 56,6\% de las mujeres con dismenorrea primaria reportó ausentismo escolar.

Conclusión: la dismenorrea primaria es un problema común en la población adolescente de Tbilisi, Georgia. Los resultados de este estudio demostraron que las adolescentes con dismenorrea primaria en la experiencia de Georgia tienen puntajes significativamente más bajos de calidad de vida en lo que se refiere a salud física y psicosocial en comparación con sus pares sanos.

Palabras clave: dismenorrea primaria, calidad de vida del adolescente, EQ-5D, test de calidad de vida.

\section{INTRODUCTION}

In spite of the fact that the skills and technology to relieve severe pain are advancing, unrelieved pain continues to be a problem that undermines quality of life (1) and increases healthcare costs (2). The American Pain Society defines pain as an "unpleasant sensory and emotional experience associated with actual and potential tissue damage, or described in such terms of damage" (3).

McCaffery and Beebe (4) simply define it as "anything the person with pain says it is, occurring whenever the person say it does". Pain is a subjective experience and is different for each person depending on multiple factors, including pain severity, duration, and previous pain experience. Other important factors include the presence of anxiety or depression, values and beliefs (5). Self reporting of pain is the single most important element in understanding pain.
A recent systematic review of the world literature on chronic pelvic pain reports a prevalence of dysmenorrhea ranging between $17 \%$ and $80 \%$ (6). The most recent studies conducted in adolescent women report a prevalence ranging between $20 \%$ and $90 \%(7,8)$. The precise prevalence of dysmenorrhea is difficult to elucidate because of variations in definitions and survey methodology. A previous study of our group revealed that the prevalence of primary dysmenorrhea in the adolescent population of Tbilisi, Georgia, is 51.2\% (9).

In 1948, the World Health Organization defined health as being not only the absence of disease and infirmity but also the presence of physical, mental, and social wellbeing (10). Quality of Life (QoL) is a subjective phenomenon based on individual perception, developed through experiences, beliefs, and expectations (11). The topic of quality of life entered the realm of psychosomatic research in the 1970s. Nowadays, quality of life has become an issue in many clinical studies, especially in oncology and transplantation medicine (12-15). It was demonstrated that subjective quality of life is a relevant criterion; however, there are only few studies on the topic of health-related quality of life, especially in women. Those studies refer to the context of quality of life and certain stages in life, such as childbirth and old age.

Pain, especially chronic pain, poses a unique challenge for outcomes research due to the central importance of patient-centered and patient-reported information. The diagnosis may be overlooked and the impact of primary dysmenorrhea has been poorly researched considered that studies have focused on highly selected, mainly Western populations, with small sample sizes. There are studies that describe negative effects of the disease such as absenteeism and social interactions $(16,17)$, but we consider that absenteeism does not describe the full spectrum of disease-related loss of productivity at work. So we consider it essential to measure the impact of primary dysmenorrhea on quality of life using a specific test. The standard application of valuable 
instruments will allow for comparisons of primary dysmenorrhea QoL across different ethnic groups and geographicregions. To our knowledge, no study has explored the association of gynecological pain with quality of life (QoL) among Georgian adolescents. Thus the objective of this study was to quantify the impact of primary dysmenorrhea on physical and mental health status, health-related quality of life, and work-related aspects -absenteeism and work productivity -in the adolescent population of Tbilisi, Georgia.

\section{MATERIAL AND METHODS}

Cross-sectional study involving women aged between 14 and 20 years, without previous parity and who gave written or verbal informed consent. Women were excluded if they presented acute or chronic pelvic pathology, physical illness affecting eating behavior or causing pain, any history of mental illness or a structural abnormality that could account for pain or sleep disorder, or if they were planning pregnancy or taking any kind of psychotropic drugs.

The study was conducted with two-stage cluster sampling. The primary unit of random selection was Tbilisi, the capital of Georgia. Selection of clusters used probability proportional to size (PPS) sampling, based on statistical data collected in 2008. Cluster was first used to select the schools and universities to be included. Enrolment data in these schools were obtained from the Ministry of Education. The second stage consisted of systematic equal probability sampling. Students were randomly selected from within the selected schools and were eligible to participate in the survey. A sample size of 424 women was estimated. The women were divided into 2 groups based upon their complaints; the first group (n = 276) experienced painful menstruation, whereas the second group $(n=148)$ had no physiological or somatic complaints during menstruation.

All participants received an ultrasound to rule out pelvic pathology, and a survey was used to assess essential demographic and social parameters. They were first exposed to instructions on how to fill the questionnaires. In order to achieve efficient, consistent results and facilitate comparison across populations and over time, we used a standard test: EQ-5d. The EQ-5D is a standardized generic instrument developed for describing and assessing health status. The EQ-5D was created for use in population health surveys or in conjunction with a condition-targeted instrument for the assessment of outcomes related to specific health conditions or their treatment. The first of 2 parts records patient health status in 5 dimensions (mobility, self-care, usual activities, pain/discomfort, and anxiety/depression). Each dimension has 3 levels reflecting no problem, some problem, and extreme problem. Respondents are asked to indicate one of the 3 levels for each of the 5 dimensions. This classifies respondents into 1 of 243 distinct health status descriptions. The second part of the EQ-5D is a 20-cm VAS with the following end points: "best imaginable health status" (100) and “worst imaginable health status"(0). Respondents are asked to illustrate how they rate their own health status by drawing a line to that best. The EQ-5D is generally considered suitable for children aged 12 years and over. Health status is converted into a single a single summary index by applying a formula that essentially attaches valuesto each of the levels in each dimension.

Currently there are more than 100 translated versions of the EQ-5D.All translations/adaptations of the EQ-5D are produced using a standardized translation protocol that conforms to internationally recognized guidelines. There is a questionnaire available in the local language and validated for the Georgian population. These guidelines aim to ensure semantic and conceptual equivalence and involve a forward/backward translation process and lay panel assessment. Our research has official permission from the EuroQoL Group Executive, and certified translations were provided $(18,19)$.

Variables to be measured: reproductive history, demographic features, menstrual pattern, severity of dysmenorrhea, patient's health status QoL and VAS QoL. 
Statistical Analyses: The survey data was analyzed using SPSS version 13.0. Mean and standard deviations were used used for quantitative variables and proportions were used for categorical variables. Stratification by age was performed. Mean values and standard deviations were analyzed using the Independent Samples T-Test.

Informed consent was obtained from the respondents. Participants were assured of confidentiality and anonymity. The study was approved by the institutional research ethics committee. The study was conducted in accordance with the basic principles of the Helsinki Declaration.

\section{RESULTS}

Prevalence of dysmenorrhea by age group is presented in (figure 1). The groups were different in terms of age and menstrual flow duration (table 1). The exposed group recorded 39 health status descriptions compared with 15 in the control group. The group with dysmenorrhea had a significantly lower value for quality of life $(0.69 \pm 0.20)$ compared with the control group (0.94 \pm 0.10$)$. Regarding the quality of life VAS, the women with dysmenorrhea also had a significantly lower value of $74.38 \pm 17.83$ vs. 87.02 \pm 12.03 for the control group (table 1). Absenteeism caused by primary dysmenorrhea was $56.88 \%$ vs.43.12 among healthy adolescents, $\mathrm{p}<0.03$.

\section{DISCUSSION}

The results of this study demonstrated that adolescents with primary dysmenorrhea in Georgia experience significantly lower physical and psychosocial healthrelated QoL than their healthy peers.

Comparison of our results with previous studies is challenging for several reasons. Despite the fact that health-related quality of life is a multidimensional concept that encompasses physical, emotional, and social aspects associated with a given disease or its treatment (20), to date, very few studies have assessed the functioning and wellbeing of women with primary dysmenorrhea. So far, few studies in gynecology have focused on measuring quality of life and looking into the disease from a broader perspective. QoL has been studied in women suffering from breast cancer (21), in postmenopausal women (22) and in pregnant women in general $(23,24)$.

To quantify the impact of pain, various instruments (e.g., SF-36, SF-12, EQ-5D, Duke Health Profile) have been used to measure effects on QoL. Consequently, it

Figure 1

Prevalence of Dysmenorrhea by age group

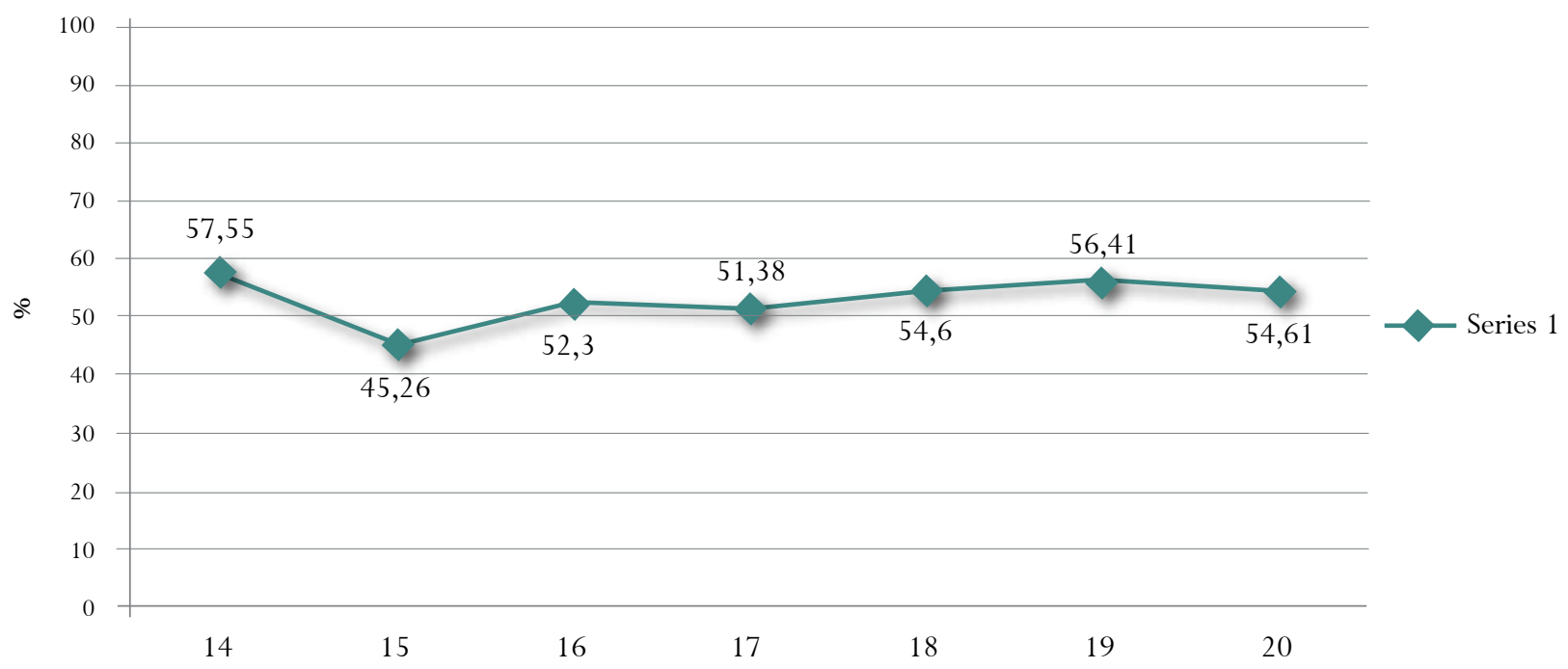




\begin{tabular}{|c|c|c|c|}
\hline \multicolumn{4}{|c|}{$\begin{array}{l}\text { Characteristics of menstrual function and quality of life in women with } \\
\text { dysmenorrhea and in healthy controls }\end{array}$} \\
\hline Variable & $\begin{array}{l}\text { Dysmenorrhea Group } \\
\qquad \mathbf{n}=276\end{array}$ & $\begin{array}{l}\text { Control Group } \\
n=148\end{array}$ & P value* \\
\hline Age & $15.55 \pm 0.86$ & $16.03 \pm 1.39$ & 0.00002 \\
\hline Menarche & $12.58 \pm 1.02$ & $12.74 \pm 1.063$ & 0.12984 \\
\hline MEMM Menstrual flow duration & $4.917 \pm 1.36$ & $4.527 \pm 1.24$ & 0.00403 \\
\hline Quality of life & $0.69 \pm 0.2$ & $0.93 \pm 0.10$ & 0.00000 \\
\hline Quality of life VAS & $74.38 \pm 17.8$ & $87.02 \pm 12.03$ & 0.00000 \\
\hline
\end{tabular}

* Independent samples T-test.

is difficult to compare our results with those of studies where other instruments were used.

It is well known that diseases accompanied by pain are associated with low quality of life scores (25). Given that dysmenorrhea is defined as chronic pelvic pain, our results are consistent with data provided by Reiter, 1998, in that it has a major adverse impact onQoL, as a result of its association with years of disability and suffering, loss of employment and marital discord (26). Zondervan et al., 2001 also described the negative effects of chronic pelvic pain, frequently requiring psychological, medical or operative interventions (27).

There are studies where the impact of primary dysmenorrhea on quality of life was analyzed using the SF-36 test, showing low scores for physical function, physical pain, general health perception, vital function, with no differences in social functioning, emotional and mental parameters (28). Bernard, using the same measurement tool, found low scores in all dimensions compared with the healthy population (29). Even though there is a lack of studies with specific, quantitative results, the high prevalence of primary dysmenorrhea and its impact on health, work productivity, and activities of daily living has already been described in qualitative studies. Collectively, these studies conclude that primary dysmenorrhea has a substantial detrimental effect on productivity (30). Dysmenorrhea is the leading cause of recurrent short-term school absenteeism among adolescent girls (16). Similar re- sults were observed in Taiwanese adolescents, with loss of concentration in 64.6\%, no participation in extra-curricular activities in 25\%, and school absenteeism in $8.88 \%$ (31). Our study supports the evidence gathered by qualitative studies conducted in other populations, indicating that primary dysmenorrhea-related symptoms have a negative impact on QoL and work productivity.

\section{Weakness and strengths of the study}

The fact that the population of this study is epidemiologically representative of the adolescents of Tbilisi, Georgia, is a strength.Although comparison between the main variables was cross-sectional, the sample size was sufficient to allow detection of a standardized difference smaller than 0.4 between two means, for a $p$ value of 0.05 and power of $80 \%$. This quantitative study provides tangible evidence of the negative impact of primary dysmenorrhea on important aspects related to daily life, as shown qualitatively before.

Cross-sectional data is a weakness of the study because it does not allow examination of changes over time. The fact that the questionnaire does not contain age-specific questions is another weakness.

\section{CONCLUSION}

Our research demonstrated that primary dysmenorrhea negatively affects many aspects of physical and mental health in adolescents in Tbilisi, Georgia. Highlighting these negative effects will result in 
more timely diagnosis and treatment. The qualityof-life measurment tool can be used to evaluate the effectiveness of pain treatment and guide the selection of pharmacologic and non-pharmacologic therapies.

Acknowledgments: We wish to express our gratitude to all the participants, their teachers, and school principals who have been very supportive.

\section{REFERENCES}

1. Ferrell BR, Rhiner H, Cohen MZ, Grant M. Pain as metaphor for illness Part I. Impact of cancer on family and caregivers. Oncol Nurs Forum.1991;18:1303-9.

2. Ferrell BR, Grifith H. Cost issues related in pain management: Report from cancer pain panel of the agency for health care policy and Research. J Pain Symptom Manage. 1994;9:221-34.

3. Mersky H. Classification of Chronic Pain. Description of Chronic Pain syndromes and definition of pain terms. Pain. 1986;3:217.

4. McCaffery-BeebeA. Pain. Clinical Manual of Nursing Practice. St. Louis: CV Mosby; 1989.

5. Curtiss CP. Assessment of pain and pain relief: Key to successful pain control. Journal of Pharmaceutical Care in Pain \& Symptom Control. 1997;5:33-45.

6. Latthe P, Latthe M, Say L, Gülmezoglu M, Khan KS. WHO systematic review of prevalence of chronicpelvic pain: neglected reproductive health morbidity. BMC Public Health 2006;6:177.

7. Davis AR, Westhoff CL. Primary dysmenorrhea in adolescent girls and treatment with oral contraceptives. J Pediatr Adolesc Gynecol. 2001;14:3-8.

8. Banikarim C, Chacko MR, Kelder SH. Prevalence and impact of dysmenorrhea on Hispanic female adolescents. Arch Pediatr Adolesc Med. 2000;154:1226-9.

9. Gagua T, Tkeshelashvili B, Gagua D. Primary dysmenorrhea: prevalence in adolescent population of Tbilisi, Georgia and risk factors. J Turkish German Gynecol Assoc. 2012;13:162-8.

10. Testa MA, Simonson DC. Assesment of quality-of-life outcomes. N Engl J Med 1996;334:835-40.
11. Bubien RS, Knotts-Dolson SM, Plumb VJ, Kay GN. Effect of radiofrequency catheter ablation on healthrelated quality of life and activities of daily living in patients with recurrent arrhythmias. Circulation. 1996;94:1585-91.

12. Hjermstad MJ, Evensen SA, Kvaloy SO, Fayers PM, Kaasa S.Health-related quality of life 1 year after allogeneic or autologous stem-cell transplantation: A prospective study. J Clin Oncol. 1999;17:706-18.

13. Bull AA, Meyerowitz BE, Hart S, Mosconi P, Apolone G, Liberati A. Quality of life in women with recurrent breast cancer. Breast cancer Res Treat. 1999;54:47-57.

14. Archonti C, D'Amelio R, Klein T, Schäfers HJ, Sybrecht GW, Wilkens H. Gesundheits bezogene Lebensqualität und soziale Unterstu “ tzungbei Patienten auf der Warteliste und nacheiner Lungen transplantation. Psychother Psycho Med. 2004;54:17-22.

15. Härtl K, Janni W, Kästner R, Sommer H, Strobl B, Rack B, Stauber M. Impact of medical and demographic factors on long-term quality of life and body image of breast cancerpatients. Ann Oncol. 2003;14:1064-71.

16. Banikarim C, Chacko MR, Kelder SH. Prevalence and impact of dysmenorrhea on Hispanic female adolescents. Arch Pediatr Adolesc Med. 2000;154:1226-9.

17. Granot M, Yarnitsky D, Itskovitz-Eldor J, Granovsky Y, Peer E, Zimmer EZ. Pain perception in women with dysmenorrhea. Obstet Gynecol. 2001;98:407-11.

18. The EuroQol Group. EuroQol-a new facility for the measurement of health-related quality of life. Health Policy. 1990;16:199-208.

19. Brooks R. EuroQol: the current state of play. Health Policy. 1999;637:53-72.

20. Kaufman S. The emerging role of health-related quality of life. Data in clinical research, part 2. Clinical Research. 2001;1:38-43.

21. Carlsson M, Hamrin E, Lindqvist R. Psychometric assessment of the Life Satisfaction Questionnaire (LSQ) and a comparison of a randomized sample of Swedish women and those suffering from breast cancer. Qual Life Res. 1999;8:245-53.

22. Karlberg J, Mattsson LA, Wiklund I. A quality of life perspective on who benefits from estradiol 
Revista Colombiana de Obstetricia y Ginecología Vol. 64 No. 2 • 2013

replacement therapy. Acta Obstet Gynecol Scand. 1995;74:367-71.

23. Hunt SM, McEwen J, McKenna SP. Measuring health status: a new tool for clinicians and epidemiologists. J R Coll General Pract. 1985;35:185-8.

24. Hueston WJ, Kasik-Miller S. Changes in functional health status during normal pregnancy. J Fam Prac. 1998;47:209-12.

25. Skevington SM. Investigating the relationship between pain and discomfort and quality of life, using the WHOQOL. Pain. 1998;76:395-406.

26. Zondervan KT, Yudkin PL, Vessey MP, Jenkinson CP, Dawes MG, BarlowDH, etal. The community prevalence of chronic pelvic pain in women and associated illness behavior. Br J Gen Pract. 2001;51:541-7.
27. Reiter. Evidence-Based Management of Chronic Pelvic Pain. 1998:41:2:422-35.

28. Unsal A, Ayranci U, Tozun M, Arslan G, Calik E. Prevalence of dysmenorrhea and its effect on quality of life among a group of female university students. Ups J Med Sci 2010;115:138-45.

29. Barnard K, Frayne SM, Skinner KM, Sullivan LM. Health status among women with menstrual symptoms. J Womens Health (Larchmt). 2003;12:911-9.

30. Davis AR, Westhoff CL. Primary Dysmenorrhea in Adolescent Girls and Treatment with Oral Contraceptives. J Pediatr Adolesc Gynecol 2001:14:3-8.

31. Chen CH, Lin YH, Heitkemper MM et al. The selfcare strategies of girls with primary dysmenorrhea: a focus group study in Taiwan. Health Care Women Int. 2006;27:418-27.

\section{Conflict of Interest: none declared.}

